\title{
SISTEM PENJADWALAN RAPAT PIMPINAN UNIVERSITAS DENGAN METODE MATRIKS
}

\author{
Bambang Nurdewanto \\ Fakultas Teknologi Informasi, Universitas Merdeka Malang \\ nurdewa@unmer.ac.id
}

\begin{abstract}
Leadership Meeting is one of the regular activities carried out at a university. The participants of this meeting in addition to serving leader as well as a lecturer who daily burdened by student teaching activities. Often these participants complain because scheduled board meeting in conjunction with the teaching schedule in jurusan. Than it needs to be a method that is reliable and quick to perform effective scheduling by performing matrix method assisted by using the software. If using a calculation matrix operations manually adding any change or update data, requiring the repetition of a recount needs to be done carefully. But by using this software, the end result can be seen immediately, immediately formed matrix accumulation. Leaders who will be meeting participants can be chosen flexibly. Matrix data will be automatically updated after the meeting participants selected, so that the determination of the leadership meeting schedule will be more flexible and accurate.
\end{abstract}

Keywords : schedules, meetings, matrix

\section{PENDAHULUAN}

Rapat Pimpinan adalah salah satu kegiatan yang rutin dilakukan di suatu Universitas. Rapat pimpinan ini biasanya digunakan oleh rektor untuk merencanakan, memonitor, mengkoordinasi dan menginformasikan semua kegiatan Universitas.

Rapat pimpinan ini biasanya dihadiri oleh Rektor, para Wakil Rektor, para kepala Lembaga, kepala Biro, Dekan, dan juga Ketua Program Studi yang terkait dengan kegiatan yang akan diagendakan rapat. Selain menjabat sebagai pimpinan, para peserta rapat ini juga sebagai dosen yang sehari-harinya dibebani oleh kegiatan mengajar mahasiswa. Sering kali para peserta ini mengeluh karena jadwal rapat pimpinan bersamaan dengan jadwal mengajar di jurusan. Hal ini juga dikeluhkan oleh mahasiswa yang diajar dosen yang juga merangkap sebagai salah satu pimpinan Universitas, karena sering absen saat adanya rapat.

Peserta rapat juga sering terlambat atau tidak hadir pada rapat pimpinan dengan alasan masih mengajar. Penjadwalan rapat dapat dilakukan jauh-jauh hari, untuk meminimal benturan dengan jadwal mengajar para pimpinan. Diperlukan suatu pengelolaan yang tepat agar rapat dapat terlaksana dengan hemat waktu dan tenaga, serta memberikan hasil yang sesuai dengan sasaran yang diharapkan.

Dalam matematika, matriks adalah array persegi panjang angka, simbol, atau ekspresi. Item individu dalam matriks disebut elemen atau entri. Contoh matriks dengan enam elemen adalah

$$
\left[\begin{array}{ccc}
1 & 9 & -13 \\
20 & 55 & -6
\end{array}\right]
$$

Garis-garis horizontal dan vertikal dalam matriks disebut baris dan kolom, masing-masing. Angka-angka dalam matriks disebut entri atau elemennya. Untuk menentukan ukuran matriks, matriks dengan $m$ baris dan $n$ kolom disebut matriks $m \times n$ matriks, sedangkan $m$ dan $n$ disebut dimensi.

Jadwal mengajar semua pimpinan dapat diinputkan kemudian dipresentasikan dalam bentuk matrik, kemudian diakumulasikan kedalam bentuk matrik gabungan. Dari matrik gabungan ini dapat dilihat mana saja jadwal yang masih kosong atau paling sedikit nilainya. Dari nilai terkecil ini dapat dijadwalkan rapat pimpinan. Bila nilainya 0 (nol) artinya tidak ada peserta rapat yang mempunyai jadwal mengajar pada saat itu. Saat inilah waktu yang paling tepat untuk mengadakan rapat pimpinan.

Guna melakukan hal tersebut maka salah satu jalan yang bisa dilakukan adalah dengan 
melakukan penjadwalan dengan metode matrik dibantu dengan menggunakan perangkat lunak. Perangkat lunak penjadwalan tersebut digunakan sebagai perangkat pengganti perhitungan manual yang mana perhitungan manual tersebut memakan waktu dan pikiran. Oleh sebab itu penggunaan perangkat lunak sangat diperlukan untuk mengefisienkan waktu dan tenaga.

\section{METODE PENELITIAN}

Untuk melaksanaan serta menyelesaikan penelitian ini dilakukan langkah-langkah sebagai berikut :

a) Studi literatur, mempelajari mengenai :

- Pembuatan jadwal rapat

- Metode matriks

- Desain Sistem Informasi

b) Pengambilan data

- Pengambilan data jadwal mengajar di Universitas Merdeka Malang

- Analisa dan pengolahan data, disesuaikan dengan format untuk seluruh Universitas Merdeka Malang

c) Fase Desain

- Merancang user interface

- Merancang aliran data dan proses yang didasarkan pada rumus-rumus yang telah ditentukan

- Merancang petunjuk-petunjuk yang akan digunakan pada sistem

d) Fase Implementasi

Menerapkan dan mengimplementasikan rancangan yang telah dibuat didasarkan berbagai rumus dan algoritma yang disiapkan

e) Fase Analisa Hasil

Melakukan analisa terhadap jadwal rapat pimpinan yang dibuat

f) Penulisan Laporan

Melaporkan hasil penelitian yang telah dilakukan

\section{HASIL DAN PEMBAHASAN}

Jadwal mengajar masing-masing peserta rapat dimasukkan ke dalam program penjadwalan rapat pimpinan pada menu "Input Peserta Rapat". Data ini dimasukkan dengan langkah-langkah sebagai berikut :

a. Tanda cek pada "Peserta" sudah dicek secara otomatis

b. Pilih jabatan sesuai jabatan dari peserta rapat, mulai rektor sampai dekan c. Rubah nilai 1 jika pada kolom terdapat jadwal mengajar, disesuaikan dengan jadwal mengajar para peserta rapat pimpinan. Isian ini harus diupdate setiap semester

d. Biarkan nilai 0 jika pada kolom tidak terdapat jadwal mengajar disesuaikan dengan jadwal mengajar para peserta rapat pimpinan. Isian ini harus diupdate setiap semester

Isian data ini dapat dilihat pada gambar 1

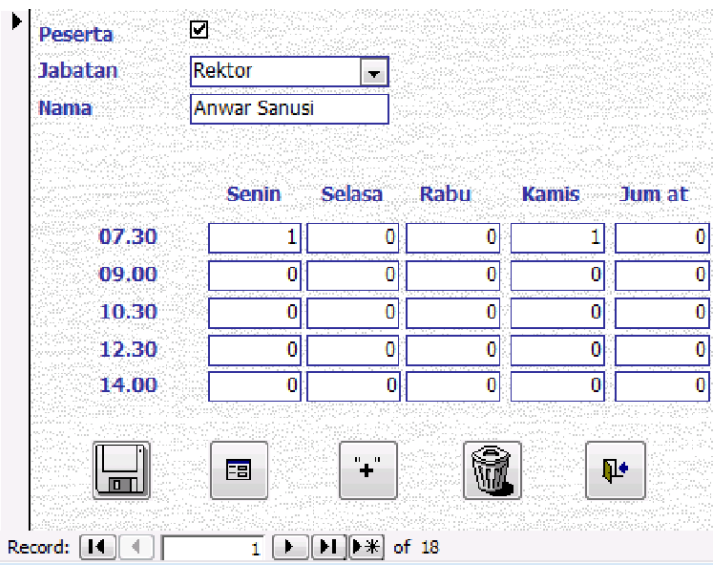

Gambar 1 Pemasukan data jadwal mengajar pimpinan

Input data jadwal mengajar ini disesuaikan dengan jadwal mengajar yang ada di Fakultas, yaitu :

a. Jam I jam 7.30-09.00

b. Jam II jam 09.00-10.30

c. Jam III jam 10.30-12.00

d. Jam 12.00-12.30 istirahat (Senin-Kamis)

e. Jam IV jam 12.30-14.00

f. Jam V jam 14.00-15.30 (kelas sore)

g. Hari Jum'at jam $11.00-12.30$ istirahat Sholat Jum'at

h. Hari Sabtu Minggu Libur

Data yang dihasilkan input ini akan dirubah menjadi data matriks $5 \times 5$. Seperti data di atas akan dikonversikan menjadi matriks sebagai berikut :

$$
\left(\begin{array}{lllll}
1 & 0 & 0 & 1 & 0 \\
0 & 0 & 0 & 0 & 0 \\
0 & 0 & 0 & 0 & 0 \\
0 & 0 & 0 & 0 & 0 \\
0 & 0 & 0 & 0 & 0
\end{array}\right)
$$


Setiap data jadwal akan dikonversikan menjadi data matrik. Kemudian semua data matriks ini akan diakumulasikan ke dalam matriks akumulasi dengan operasi penambahan matriks seperti berikut ini :

$\left(\begin{array}{lllll}1 & 0 & 0 & 1 & 0 \\ 0 & 0 & 0 & 0 & 0 \\ 0 & 0 & 0 & 0 & 0 \\ 0 & 0 & 0 & 0 & 0 \\ 0 & 0 & 0 & 0 & 0\end{array}\right)+\left(\begin{array}{lllll}1 & 0 & 0 & 0 & 0 \\ 0 & 0 & 0 & 1 & 0 \\ 0 & 0 & 0 & 0 & 0 \\ 0 & 0 & 0 & 0 & 0 \\ 0 & 0 & 0 & 0 & 0\end{array}\right)=\left(\begin{array}{lllll}2 & 0 & 0 & 1 & 0 \\ 0 & 0 & 0 & 1 & 0 \\ 0 & 0 & 0 & 0 & 0 \\ 0 & 0 & 0 & 0 & 0 \\ 0 & 0 & 0 & 0 & 0\end{array}\right)$

Setelah semua data jadwal mengajar peserta rapat dimasukkan, bila akan mengadakan rapat pimpinan dipilih dahulu peserta rapatnya dengan cara memberikan tanda cek pada peserta rapat dan menghilangkan tanda cek bagi yang tidak mengikuti rapat, seperti pada gambar 2 .

\begin{tabular}{|c|c|c|}
\hline Peserta & Jabatan & Nama \\
\hline$\nabla$ & Rektor & - Anwar Sanusi \\
\hline$\nabla$ & Wakil Rektor 1 & \begin{tabular}{|l|l|} 
- & Tutut Subadio \\
\end{tabular} \\
\hline$\square$ & Wakil Rektor 2 & - Prihat Assih \\
\hline$\square$ & Wakil Rektor 3 & - \\
\hline$\nabla$ & Ka Biro AA & $\begin{array}{ll} & \text { Triswanto } \\
\end{array}$ \\
\hline$\square$ & Ka Biro Umum & $\begin{array}{ll}\text { Harsono } \\
\end{array}$ \\
\hline$\square$ & Ka Biro AK & - Rofiq \\
\hline$\nabla$ & Ka Biro Humas & - Ana \\
\hline$\nabla$ & Ka Puskom & \begin{tabular}{l|l} 
& Fikri \\
\end{tabular} \\
\hline$\nabla$ & Ka Perpus & - Sih Hanto \\
\hline$\nabla$ & Ka Pus Bhs & - Panca \\
\hline$\nabla$ & Ka LP2M & - Harmono \\
\hline$\nabla$ & Ka BP3M & . Respati \\
\hline$\nabla$ & Dekan FH & - Supriyadi \\
\hline$\nabla$ & Dekan FE & \begin{tabular}{l|l} 
& Burhan
\end{tabular} \\
\hline
\end{tabular}

Gambar 2 Penentuan peserta rapat

Hal ini dilakukan agar matriks yang diakumulasikan dengan operasi penambahan matriks hanyalah data jadwal peserta rapat saja, dan ini disesuaikan dengan undangan rapat. Data matriks jadwal yang tidak diundang pada rapat pimpinan tidak ikut diakumulasikan dengan operasi penambahan matriks.

Setelah ditentukan peserta rapat, maka secara otomatis terbentuk matriks akumulasi. Matriks akumulasi ini dapat dapat dilihat pada menu "Cek Jadwal" pada menu "Input Jadwal Rapat". Setiap menentukan pada tanggal dan jam berapa rapat dilaksanakan, harus dilihat terlebih dahulu matriks akumulasi seperti pada gambar 3 .

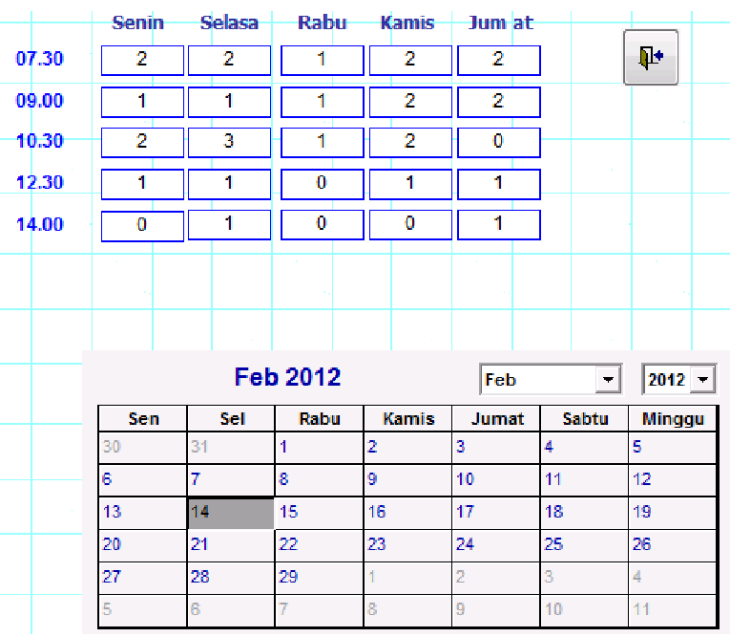

Gambar 3 Matriks Akumulasi

Pada matriks akumulasi carilah nilai terkecil yang berurutan pada kolom yang sama, nilai 0 (nol) lebih bagus jika dimungkinkan. Nilai 0 menunjukkan tidak ada jadwal mengajar pada hari dan jam itu untuk semua peserta rapat. Jika nilai 1 artinya ada satu orang yang mempunyai jadwal mengajar pada hari dan jam tersebut. Semakin besar nilainya maka semakin banyak peserta rapat yang mempunyai jadwal mengajar pada hari dan jam yang sama.

Kemudian perkirakan lama rapat itu akan berlangsung. Bila dilihat pada gambar 4.3 maka hari yang terbaik untuk rapat pimpinan adalah hari Rabu, mulai jam 12.30. Kemudian lihat kalender di bawahnya, pada tanggal berapa hari Rabu tersebut. Pada gambar 4.3 jika hari ini, hari Selasa tanggal 14 Pebruari 2012 maka hari Rabu terdekat adalah tanggal 15 Pebruari 2012. Jadi jadwal undangan rapat pimpinan yang terbaik adalah pada hari Rabu, tanggal 15 Pebruari 2012, jam 12.30.

Penentuan jadwal undangan rapat pimpinan ini disesuaikan dengan situasi dan kondisi pada saat itu. Misalnya pada hari Rabu tanggal 15 Pebruari 2012 tidak dimungkinkan dilaksanakan rapat karena suatu hal, maka alternatifnya dilihat kembali pada matrik akumulasi. Di sini terlihat alternatif lain adalah pada hari Kamis jam 12.30, tapi dengan resiko 1 orang peserta yang bersamaan jadwal mengajarnya dengan jadwal rapat. 
Pada hari Jum'at meskipun pada jam 10.30 nilainya 0 , jadwal rapat sebaiknya tidak dilakukan pada jam dan hari itu. Ini dikarenakan umat Muslim pada jam 11.00 akan bersiap melaksanakan Sholat Jum'at di Mesjid. Sehingga bila rapat dilaksanakan pada jam tersebut maka terlalu singkat waktunya dan tidak efektif.

Setelah menentukan peserta rapat pada menu "Peserta" dan melihat matriks akumulasi pada menu "Cek Jadwal", maka dapat diinputkan

a. Tanggal undangan, yaitu tanggal hari ini saat undangan dibuat. Isian ini secara otomatis diisikan sesuai dengan tanggal komputer, tapi dapat dirubah sesuai kebutuhan

b. Tema rapat, yang disesuaikan dengan rapat yang akan dilaksanakan, misalnya : Penerimaan Maba

c. Tanggal rapat, yaitu tanggal pelaksanaan rapat pimpinan yang sudah ditentukan setelah melihat matriks akumulasi pada menu "Cek Jadwal"

d. Jam rapat, yaitu jam pelaksanaan rapat pimpinan yang sudah ditentukan setelah melihat matriks akumulasi pada menu "Cek Jadwal"

e. Kemudian dapat dapat disimpan atau dihapus jika terjadi kesalahan

Input undangan rapat ini dapat dilihat pada gambar 4.

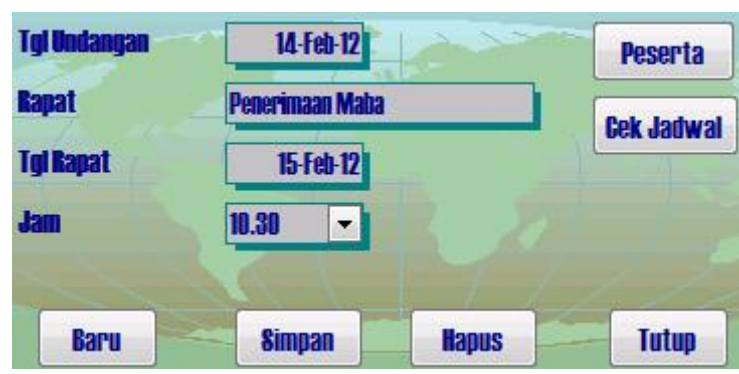

Gambar 4 Penentuan Jadwal Undangan Rapat

Berdasarkan simulasi ini maka terdapat beberapa pembahasan yang bisa dilakukan untuk bisa mendapatkan simpulan yang sesuai dengan tujuan penelitian yang ingin dicapai. Adapun penelitian tersebut adalah sebagai berikut:

1. Jika proses perhitungan penentuan jadwal rapat pimpinan dilakukan secara manual maka diperlukan tahapan-tahapan perhitungan matematik sederhana yaitu operasi penambahan matriks untuk menjadi sebuah matriks akumulasi. Meskipun operasi penghitunganya sederhana tetapi dikarenakan data yang akan dihitung banyak, hal tersebut mempunyai peluang kesalahan yang cukup besar dan waktu yang cukup lama. Sedangkan dengan menggunakan perangkat lunak Microsoft Access ini maka hal tersebut dapat dikerjakan dengan benar dan cepat secara keseluruhan.

2. Untuk mendapatkan hasil yang akurat maka diperlukan data jadwal mengajar pimpinan yang menjadi peserta rapat yang terbaru. Untuk itu setiap semester diperlukan update data jadwal mengajar dari masing-masing pimpinan dan mungkin juga update nama pimpinan apabila terjadi pergantian pimpinan. Dengan demikian, hasil dari perangkat lunak tersebut akan memberikan hasil maksimal.

3. Jika dengan menggunakan perhitungan operasi penambahan matriks secara manual setiap ada perubahan atau update data, memerlukan pengulangan penghitungan kembali yang perlu dilakukan secara teliti. Tetapi dengan menggunakan perangkat lunak ini maka hasil akhir langsung dapat dilihat, matriks akumulasi langsung terbentuk.

4. Pimpinan yang akan menjadi peserta rapat dapat dipilih dengan fleksibel. Data matriks akan otomatis terupdate setelah peserta rapat dipilih, sehingga penentuan jadwal rapat pimpinan akan lebih fleksibel dan akurat.

5. Meskipun pada kondisi tertentu, penentuan jadwal rapat pimpinan dengan perangkat lunak ini tidak dapat menghilangkan 100\% waktu yang bersamaan dengan waktu mengajar pimpinan, tetapi dapat meminimalkan jumlah pimpinan yang bersamaan dengan jadwal mengajarnya

\section{KESIMPULAN}

1. Penggunaan perangkat lunak penjadwalan rapat pimpinan dengan metode matriks dapat mempercepat menentukan jadwal rapat pimpinan secara akurat.

2. Perangkat lunak ini akan mengurangi jumlah absen mengajar dosen yang menjadi pimpinan yang dikarenakan harus hadir pada rapat pimpinan.

3. Perangkat lunak ini akan menambah jumlah presensi rapat pimpinan, karena lebih banyak dosen yang dapat meluangkan waktunya hadir pada rapat tanpa meninggalkan jadwal mengajarnya. 


\section{REFERENSI}

[1] http://en.wikipedia.org/wiki/Matrix

(mathematics)

[2] http://purie-rapat.blogspot.com/2009/08/

pengertian-rapat.html

[3] Jogiyanto H. M 2001. Analis dan Desain Sistem Informasi : Pendekatan Terstruktur Teori dan Praktek Aplikasi Bisnis. Edisi Kedua.

Yogyakarta. Andi 